\title{
The Rhinoceroses of Ngorongoro Crater
}

\section{By Hans and Ute Klingel}

NGORONGORO Crater in Northern Tanzania is one of the few places left in Africa where the black rhinoceros is still frequent and can be regularly seen and photographed by the visitor. The crater floor, an area of 100 square miles, is the home of a great variety of game animals. Most numerous are the wildebeest which numbered over 14,000 in the aerial count made by Watson and Turner in 1964. The same count showed more than 5,000 zebra in the cratter, 2,000 gazelle, 350 eland, 50 kongoni, 30 hippopotamus, 20 elephant, 25 lion and also waterbuck, mountain reedbuck and steinbuck.

While studying the zebra in the crater, we were able to observe the rhinos as well, and from June 1963 to May 1965 we recorded and mapped all the rhinos seen on the crater floor. Some of the results of this study are given here.

\section{Identification}

One of the most important problems was how to identify and recognise individual rhinos. We found that the shape of the horns, crippled or otherwise deformed ears, prominent scars on the body, the state of the tail and the sex of the animal provided sufficient details for the recognition of all individuals in this small population. We used a system of file cards, each with close-up photographs (taken with a $400 \mathrm{~mm}$ Novoflex lens) of the head of the animal from both sides, and a detailed description of its other charadteristics. Mr John Goddard, of the Tanzania Game Division, is continuing the work with a duplicate set of our file cards.*

\section{Numbers}

The rhinos were counted in January, 1958, by Grzimek \& Grzimek (1960), who located 19 and quoted Molloy's estimate of 42 in March, 1959. These figures are not contradictory, for during our two-year observation we have found great fluctuations in the numbers seen in one day. We recorded a total of 61 different rhinos including 11 calves and subadults. Of these, 34 ( 25 adults and nine calves) were regularly seen during the whole time of observation or at least for periods of several months; they are considered to be more or less permanent residents of the crater floor. An additional 27 rhinos, including two calves, were recorded for short periods or only once; they are obviously animals which entered the crater from the surrounding highlands and then returned there. During an aerial count on February 18th, 1964, a maximum of 27 different rhinos were seen in the one

* Some photographs of rhino heads were published in ORYX, Vol. VIII, No. 3, December, 1965, together with an account of the crater by the former Conservator, $\mathrm{Mr}$ H. A. Fosbrooke. 


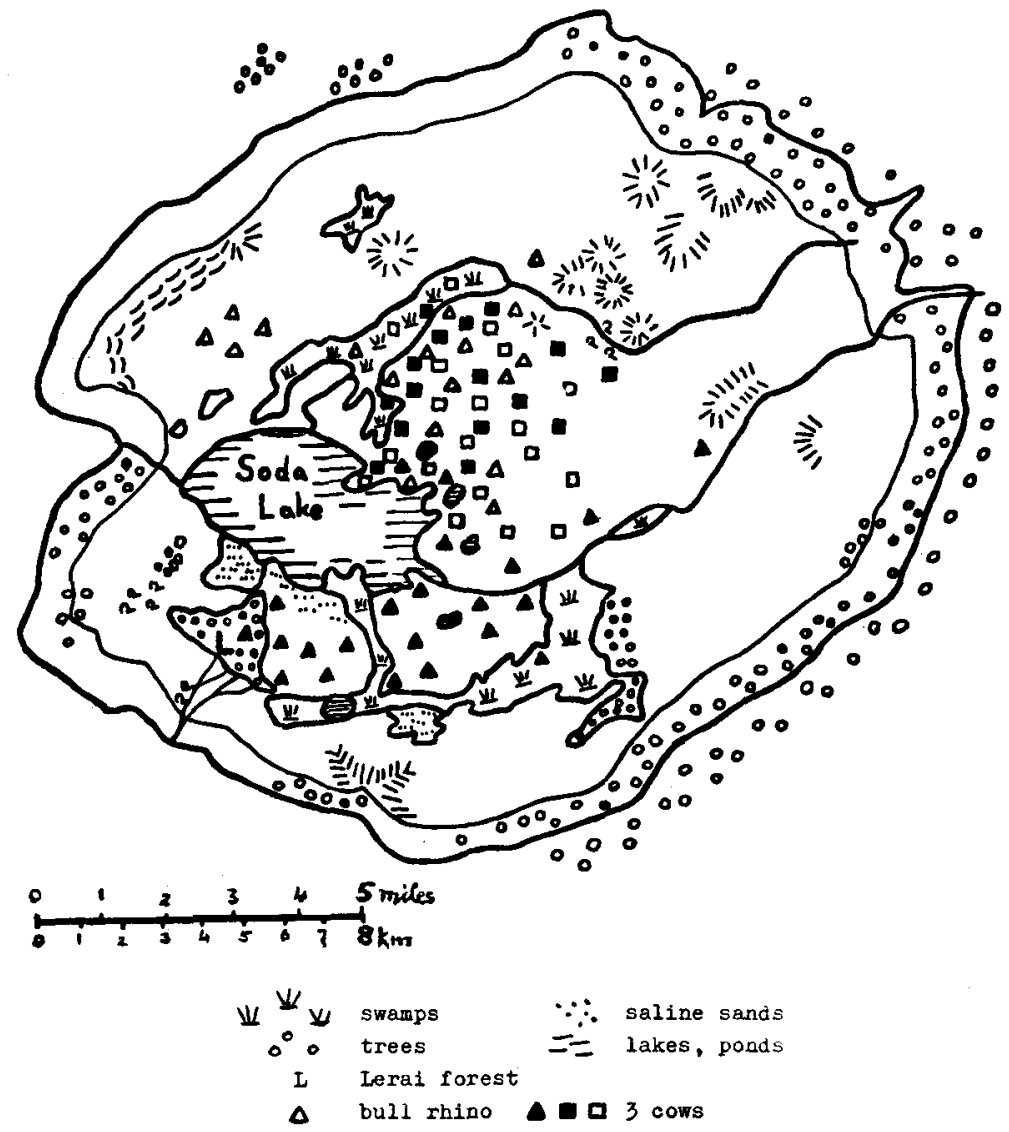

day (Turner and Watson, 1964); on October 8th, 1963, a minimum of ten were seen. This, together with other observations, suggests that even some of the permanent residents move out of the crater temporarily, probably because of adverse conditions in the height of the dry season.

Density and Distribution

Of the 101.6 square miles of the crater floor, approximately four are covered by the soda lake. This leaves a feeding area of 97 square miles to the rhinos, of 3.9 square miles to each of the residents (disregarding suckling calves). During the rains rhinos were found in all parts of the crater, whereas in the dry season they tended to move nearer the crater wall and also into the swamps. Up to eight animals were seen simultaneously in Lerai Forest. The irregular visitors were found mainly in the hilly areas along the eastern and northern crater wall. 


\section{Associations}

Most of the rhinos were solitary and in roughly the same area. The maximum number seen together and identified was five: three adult cows, a calf and one adult bull on one occasion, two adult cows, a calf and two adult bulls on another. Both groups broke up after a few days. Groups of four rhinos were seen repeatedly but they also usually disbanded after a short time. In a few instances individuals other than cow and calf stayed together for a considerable time; a bull, a cow with calf and a subadult bull were recorded together for four months. Two adult cows, possibly mother and daughter, were seen together for 13 months; one of them is the animal whose history is given below (1). A cow with a half-grown bull calf was recorded in July and August 1963, and then disappeared. Eight months later the cow reappeared with a newly born calf. The elder bull calf was seen again 18 months after having disappeared, almost fully grown. He then associated with another cow and calf: see (2) below. From the limited data it can only be suggested that subadults separate from their mothers at the time when a new calf is born. Three examples from the whole group demonstrate the variety of associations of individual animals:

1. Adult cow. She was reconded as being solitary from June to October 1963. In November we found her associating with another cow, possibly her daughiter, with whom she stayed for over a year till January 1965, thereafter she was by herself till May 1965 . However, during the time the two were together they were once joined by a cow and the bull whose history is given below (3), and later by another cow with calf and a bull. This bull stayed on for at least 15 days, whereas the cow and calf went their own ways after abbut four days.

2. Adult cow. Also solitary or together with an adult bull from July 1963 to September 1964, when the two were joined by a cow with calf and another adult bull. In December 1964 she had a calf and the two separated from the bull. Shortly afterwards they were joined by the subadult bull mentioned above and a little later by another adult bull. They all stayed together, with intervals, for at least four months.

3. Adult bull. Solitary from July to November 1963, then with three cows. A month later he was by himself, then joined up with two other cows, then with another cow with call and finally was solitary again from March to May 1965.

\section{Sex Ratio and Recruitment}

The overall sex ratio of the permanent residents including calves and subadults was 17 males to 17 females, that of the adults 11 males to 14 females. From these figures, and also from the fact that males and females are rather evenly distributed over the crater floor, it cannot be concluded that, at the present density of rhinos, males emigrate out of the crater at a higher rate than females. In 1963 there were no new-born calves in the population, and only one animal was con- 


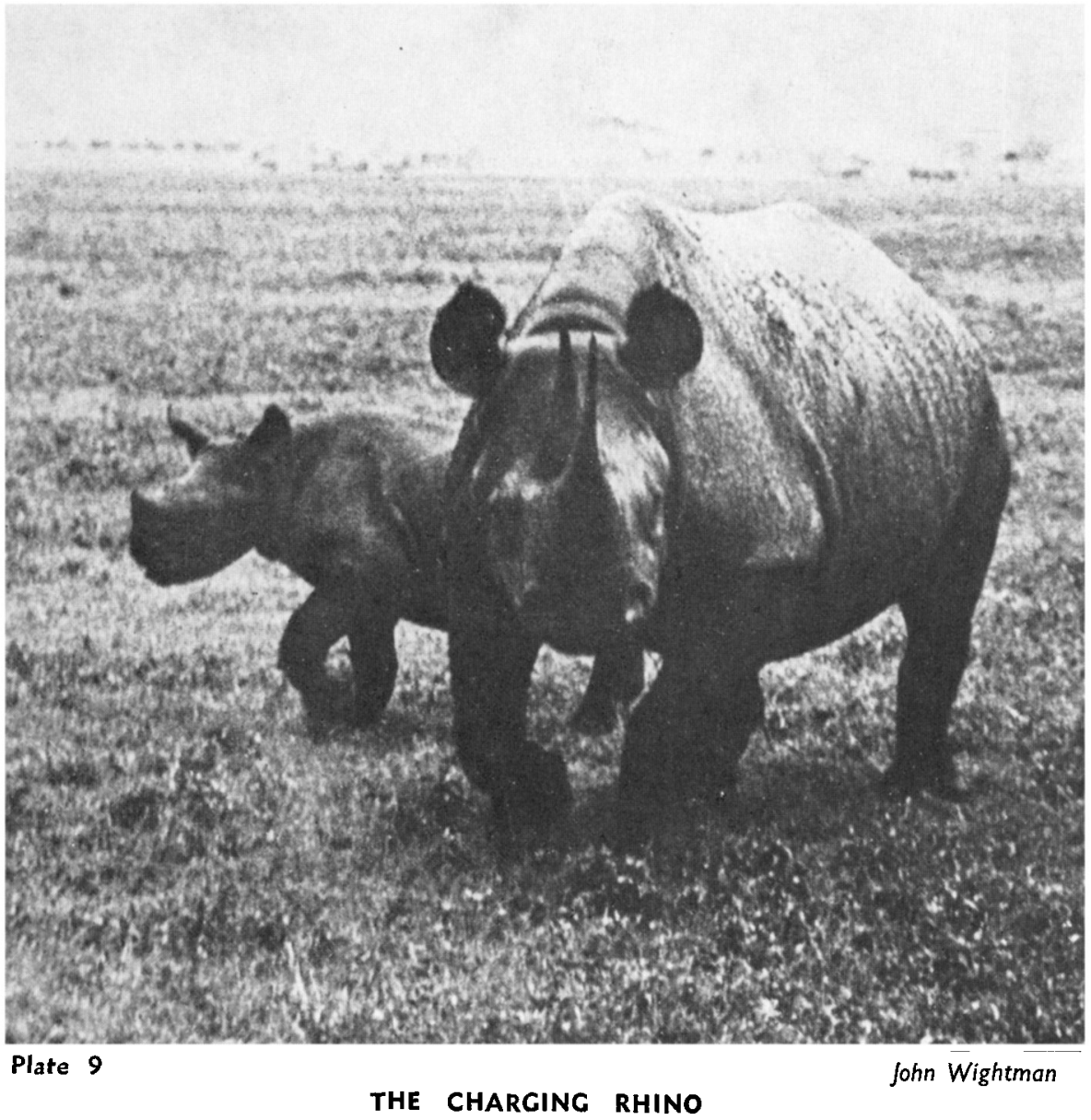

An incident in the Ngorongoro Crater during the FPS East African tour last February. This rhino decided that the FPS Land Rover was too close to her calf and charged it. The driver had to make a quick getaway. 


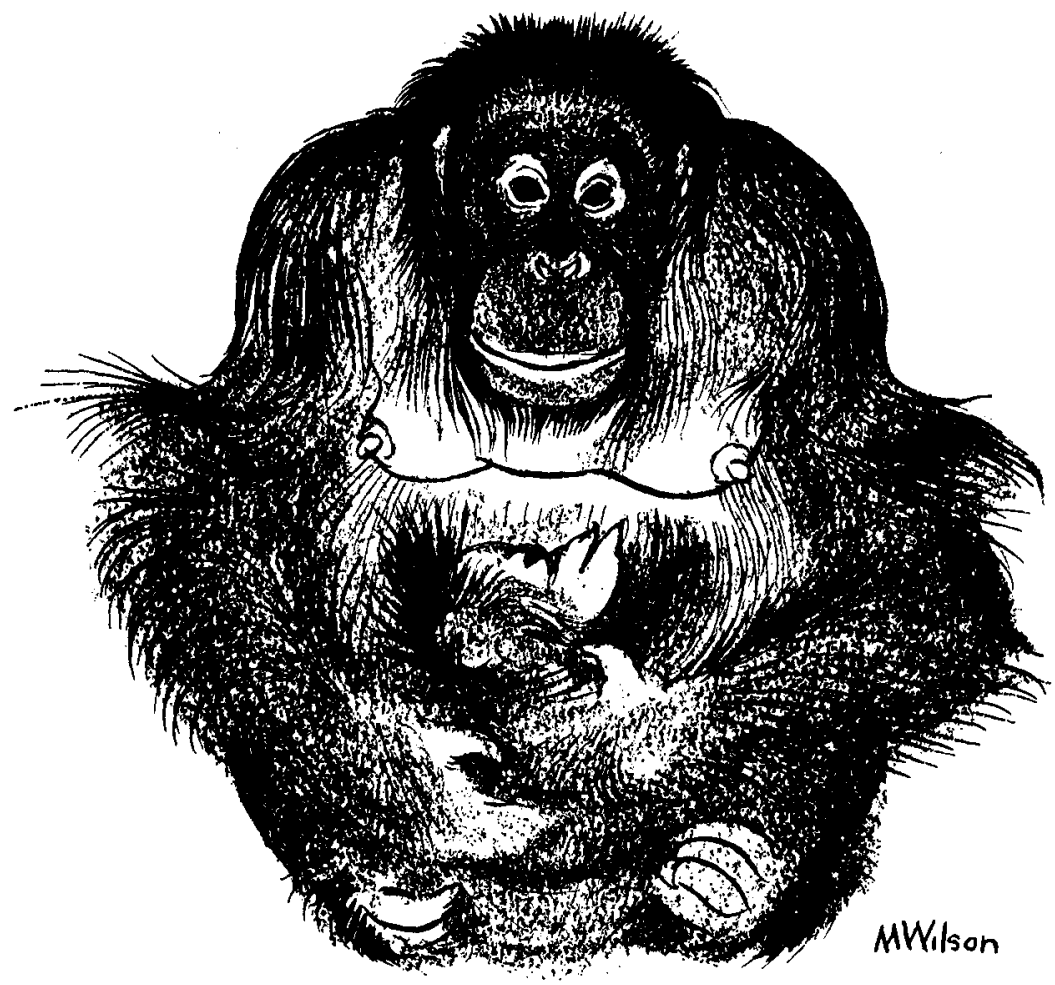

Plate 10

ORANG UTAN-MOTHER AND CHILD

Maurice Wilson's design for the FPS black and white Christmas card. 6s. per dozen. 


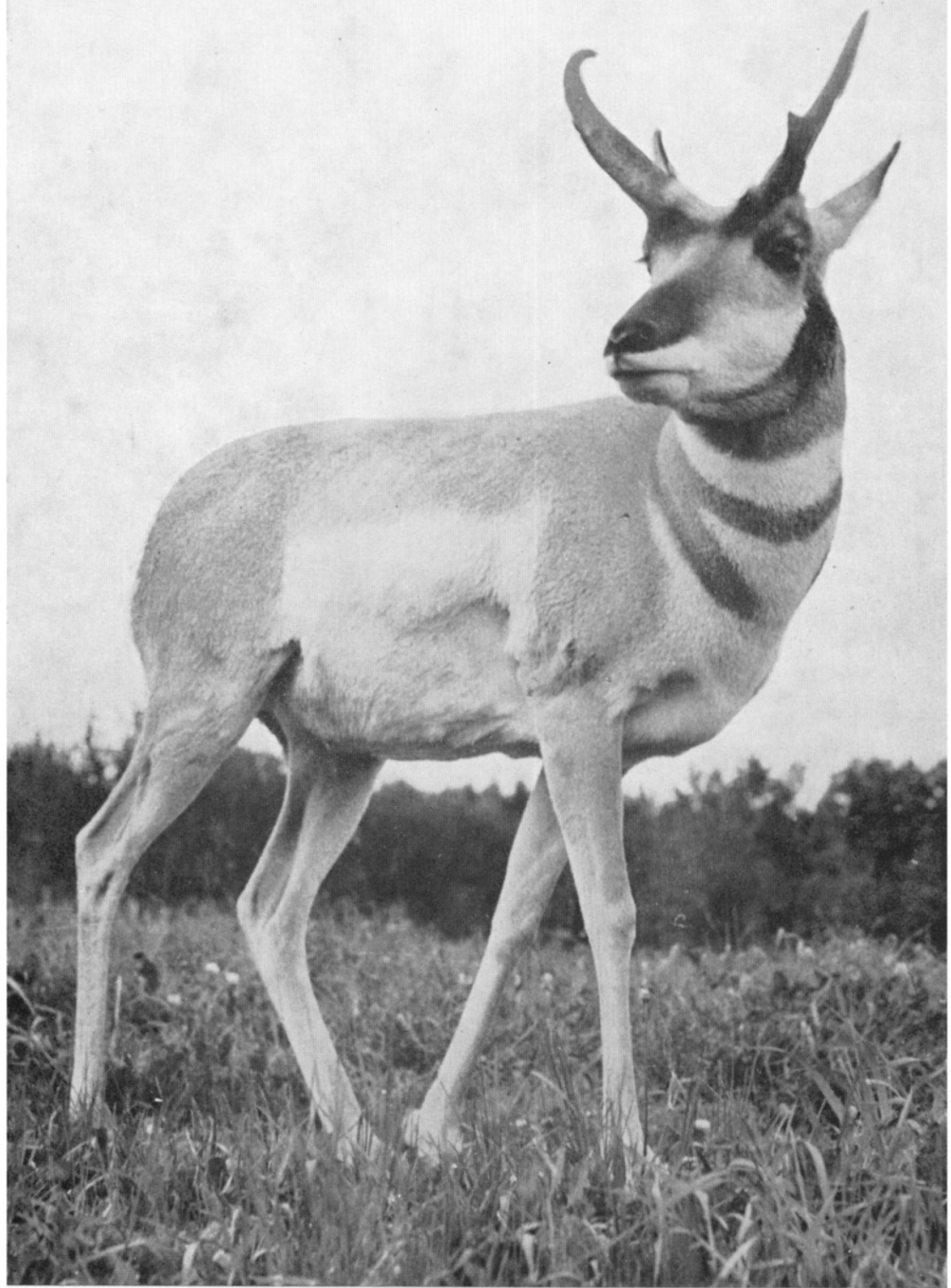

THE PRONGHORN ANTELOPE-a "saved" American species. In 1924 numbers of this antelope were down from millions to about 26,000; now they are thought to be over 300,000 . But to-day there are new threats for this creature of the wide open spaces: the increase in fences on the prairies, where formerly cowboys guarded the grazing domestic herds, which block the antelopes' migration routes, and herbicides. This photograph, by Dr Bernhard Grzimek, is in his new book reviewed on page 315 . 
sidered subadult. During the two years eight calves were born in the resident population, all during the rainy season (December to May). On the average, according to these figures, 28 per cent. of the females bred per year. This is a remarkably high reproductive rate, as the rhinos are slow breeders, taking about five years to reach maturity, and having a gestation period, according to records from zoological gardens, of over 18 months. If, for a few years, conditions remain as favourable as they seem to be now, and if poaching can be suppressed, the population can be expected to increase, thus making the area even more altractive to visitors and also, by the emigration of individual animals, stocking up the surrounding areas.

Feeding

Rhinos are known to browse and graze as well. Food specimens and dung were collected tor subsequent analysis and determination, the results of which will be published elsewhere. In addition to the stated feeding habits, we found rhinos also to be coprophagous, i.e. dung eating, a most unusual habit in a wild herbivore. For several days a group of four animals was observed repeatedly eating wildebeest droppings. During the time these observation were made, several hundred wildebeest were feeding in the area, which, following a grass fire, had only a very short grass cover of up to three inches long. The rhinos selected fresh or superficially dried dung. They picked a whole heap of dung from the ground and chewed it, losing parts of it in the process, but swallowing most of it. Whilst engaged in this activity, they did not feed on any plant, but walked determinedly from one dung heap to the next. The reason for this extraordinary behaviour is not known, but possibly a mineral or other deficiency is balanced in this manner.

Territorial Behaviour

Most of the permanent residents lived within well-defined home ranges; this was particularly true for the bulls. The map shows the places where four individuals were recorded during the two years of observation. In several instances animals of both sexes moved out of one area and settled down in another. Many of the bulls were never recorded outside their ranges, and it is possible that they establish true territories. Further investigations are necessary to solve this problem. There seems to be little antagonism between neighbouring bulls, and they do not attack trespassers. At this stage it is not possible to assess the significance of the dung eating. Bulls and also cows were observed using the same defecation places over and over again, and spreading the dung with their hind legs in the well known manner. Obviously this behaviour serves to mark the home range of an individual, which, however, often overlaps with that of a neighbour. We have observed cows, but not other bulls, using the defecating place of a bull.

At present the black rhinoceros is not in danger of extinction in East Afrioan game sanctuaries, although it has become very rare else- 
where. For effective protection of the species the knowledge of its biology and habits is of basic importance, and all information relating to them should be collected.

\section{Scientific Names of Species Mentioned \\ Black rhinoceros $\quad$.. $\quad$.. Diceros bicornis \\ Wildebeest $\quad . . \quad \ldots \quad$.. $\quad$ Connochaetes taurinus albojubatus

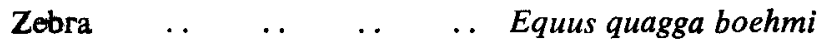

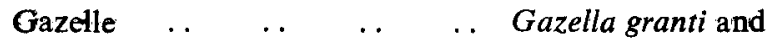 Gazella thomsoni \\ $\begin{array}{llllll}\text { Eland } & \text {. } & \text {. } & \text {. } & \text {. } & \text { Taurotragus oryx pattersonianus }\end{array}$ \\ Kongoni $\quad . . \quad$.. $\quad$.. $\quad$.. Alcelaphus buselaphus cokei \\ Hippopotamus .. $\quad$.. $\quad$.. Hippopotamus amphibius

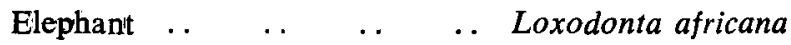 \\ Lion $\quad . . \quad$.. $\quad . . \quad$.. Panthera leo \\ Waterbuck $\quad$.. $\quad$.. $\quad$.. Kobus defassa \\ Mountain reedbuck $\quad$. $\quad$. $\quad$ Redunca fulvorufula \\ Steinbuck .. $\quad$.. $\quad$.. $\quad$.. Raphicerus campestris}

\section{References}

GRZIMEK, M., and GRZIMEK, B. (1960): A study of game of the Serengeti plains. Z. Säugetierkunde 25 , Sonderheft.

TURNER, M., and WATSON, M. (1964): A census of game in Nigorongoro crater. E. Afr. Wildl. J. 2, 165-168.

\section{A Polluted River Cleaned}

A heartening story of how a polluted river in industrial Lancashire has been cleaned up by local effort so that trout can now breed in it is told by Captain T. B. Thomas in The Field. The Colne Water flows from the Pennines through Colne and Nelson to the River Ribble. In the early 1950's some people in Colne noticed that their polluted river was running cleaner-probably as a result of changes in the cotton industry which had led some mills to close, others to switch to new products. In 1952 they formed the Colne Valley Angling Society and tackled the local Town Council and the riparian mill owners, for though pollution was less it was still considerable. The Council pushed forward the building of a new sewage works; a large tannery installed a new purification plant; other improvements followed, and the water become clean enough for stocking - once the old bedsteads had been removed. Today trout are being caught right up against the mill walls and in the centre of the town of Colne itself. Downstream at Nelson there has been a drive on similar lines, and in 1965 sea trout came up the Colne Water, probably the first time for a century at least. 